This is an electronic reprint of the original article. This reprint may differ from the original in pagination and typographic detail.

Author(s): Hämäläinen, Raija; De Wever, Bram; Nissinen, Kari; Cincinnato, Sebastiano

Title: $\quad$ Understanding adults' strong problem-solving skills based on PIAAC

Year: $\quad 2017$

Version:

Please cite the original version:

Hämäläinen, R., De Wever, B., Nissinen, K., \& Cincinnato, S. (2017). Understanding adults' strong problem-solving skills based on PIAAC. Journal of Workplace Learning, 29(7/8), 537-553. https://doi.org/10.1108/JWL-05-2016-0032

All material supplied via JYX is protected by copyright and other intellectual property rights, and duplication or sale of all or part of any of the repository collections is not permitted, except that material may be duplicated by you for your research use or educational purposes in electronic or print form. You must obtain permission for any other use. Electronic or print copies may not be offered, whether for sale or otherwise to anyone who is not an authorised user. 


\section{emeraldinsight}

\section{Journal of Workplace Learning}

Understanding adults' strong problem-solving skills based on PIAAC

Raija Hämäläinen, Bram De Wever, Kari Nissinen, Sebastiano Cincinnato,

\section{Article information:}

To cite this document:

Raija Hämäläinen, Bram De Wever, Kari Nissinen, Sebastiano Cincinnato, "Understanding adults' strong problem-solving skills based on PIAAC", Journal of Workplace Learning, https://doi.org/10.1108/JWL-05-2016-0032

Permanent link to this document:

https://doi.org/10.1108/JWL-05-2016-0032

Downloaded on: 16 October 2017, At: 04:42 (PT)

References: this document contains references to 0 other documents.

To copy this document: permissions@emeraldinsight.com

The fulltext of this document has been downloaded 4 times since 2017*

Access to this document was granted through an Emerald subscription provided by emerald-srm:306933 []

\section{For Authors}

If you would like to write for this, or any other Emerald publication, then please use our Emerald for Authors service information about how to choose which publication to write for and submission guidelines are available for all. Please visit www. emeraldinsight.com/authors for more information.

\section{About Emerald www.emeraldinsight.com}

Emerald is a global publisher linking research and practice to the benefit of society. The company manages a portfolio of more than 290 journals and over 2,350 books and book series volumes, as well as providing an extensive range of online products and additional customer resources and services.

Emerald is both COUNTER 4 and TRANSFER compliant. The organization is a partner of the Committee on Publication Ethics (COPE) and also works with Portico and the LOCKSS initiative for digital archive preservation.

*Related content and download information correct at time of download. 


\section{Understanding adults' strong problem-solving skills based on PIAAC}

\section{Purpose}

Research has shown that the problem-solving skills of adults with a vocational education and training (VET) background in technology-rich environments (TREs) are often inadequate. However, some adults with a VET background do have sound problem-solving skills. The present study provides insight into the socio-demographic, work-related, and everyday life factors that are associated with a strong problem-solving performance.

\section{Design/methodology/approach}

The study builds on large-scale data of the Programme for the International Assessment of Adult Competencies (PIAAC) and gives insight into VET adults $(\mathrm{N}=12,929)$ with strong problem-solving skills in eleven European countries.

\section{Findings}

This study introduces new knowledge with respect to the socio-demographic, work-related, and everyday life background factors that contribute to successful VET adults' problem-solving skills. Our findings illustrate that a continuous process of development including non-formal and informal activity as well as learning taking place at work is associated with strong performance in problemsolving skills in TRE.

\section{Originality/value}

An important implication of this study is that this article explored new knowledge about good problem-solvers in TREs with a VET background and can be used to support the development of VET adults' problem-solving skills in TREs.

Keywords: working life, vocational education and training (VET), technology-rich environments, the Programme for the International Assessment of Adult Competencies (PIAAC), large-scale assessment, problem-solving skills

Article category: Empirical research article. 


\section{Theoretical background}

According to Billett (2006), the requirements for professional skills and competences are increasing in all forms of work. In current working life, more high-level skills are required than ever before (OECD; 2012a). The global workplace is developing radically. For example, while the industrial sector in Europe was previously strongly based on mass-production technology, it is currently moving towards more and more flexible production methods. As a direct result of this advancement, most countries with advanced industrial sectors need to increase their flexibility and the adaptability of their jobs and ways of effective work (Harteis and Billett, 2013). The interesting question for future working life in Europe involves how well adults' vocational skills and professional expertise match the changing needs of the workplace. There is a critical notion that if adults' expertise and future workplace needs do not match, this will result in three extremes: either (1) workers will have to change occupations and complete different training programmes because their previous jobs have been outsourced or replaced by technology (Bresnahan et al., 2002; Crafts, 2004), (2) workers will stay at the same workplace, but their job descriptions will change considerably (Maclean and Wilson, 2009; Tuomi-Gröhn and Engeström, 2003), or (3) at the worst case workers will be excluded from the labour market due to their insufficient skills and abilities (OECD, 2012a). In all these cases, the current European workplace is challenging adults' expertise (Tynjälä, Häkkinen \& Hämäläinen, 2014), and there seems to be a continuing rise in workers' need for better interpersonal and cognitive skills (OECD 2012a). Thus, professional development is a key approach in helping adults to meet the needs of working life. Therefore, we need novel ways to enhance lifelong, life-wide, and workplace learning. In practice, to meet the changing workplace needs, the interest in research focusing on learning taking place at work, through work, and for work has considerably increased over the past two decades (Tynjälä, 2013).

Probably one of the greatest challenges in current working life is related to technological development. As argued before, the current trend at the workplace seems to be that workers are needed to accomplish non-routine tasks (Goos, 2013). As a direct result of this development, work tasks may become less fixed (Billett, 2006). In the case of adults with vocational education and training (VET) (e.g. in the industrial context often previously performing in-routine, intensive work tasks), an increasing amount of work tasks are now automated (Frey and Osborne, 2013). On the other hand, the current technological development not only involves new challenges for VET workers, but also new opportunities. For example, technological development and access to the open Internet have created new possibilities for entrepreneurs with a VET background. An increasing number of small business services (e.g. hairdressing, restaurants and 
bars) are gradually starting to use electronic booking systems and taking advantage of social media (e.g. using Facebook for marketing). Furthermore, at their best, with the aid of new technologies small companies are gaining access to global markets (Kende, 2015). As a direct result of this advancement, VET workers (e.g. small business owners) may increasingly benefit from their technological skills and abilities. In line with this, competence needs are changing because the ways of working are changing (OECD, 2012a). The demand to deal with emerging technical solutions is rising, and workers feel the need to develop professional competencies to deal with the evolving characteristics of technology (e.g. Kende, 2015; Herder Koesling et al., 2006; Brand-Gruwel and Stadtler, 2011).

Currently, skills for handling and producing new information as well as for solving problems play an increasingly important role in working life (Tynjälä, 2013). Even though technology can diminish the need for problem-solving in some cases, new and other forms of problem-solving needs may also emerge because of the technologies. According to Brand-Gruwel and Stadtler (2011), solving 21st century information-based non-routine problems requires multiple cognitive skills, from searching and evaluating to integrating information. As a result, an increasing amount of VET professions' workers need to engage in innovative and transformative forms of learning and problem-solving (in addition to reproductive activities) to respond to these challenges (Tynjälä, 2013). Furthermore, while the production processes are also speeding up, workers need to solve complex problems more and more rapidly. Therefore, professional expertise and abilities regarding intuitive problem-solving are becoming increasingly important. This means that in contrast to highly cognitive demanding and thus very conscious problem-solving activities, these intuitive problem-solving activities should be carried out in a more natural and spontaneous way, leading to more unconscious and very quick reactions in challenging situations (Harteis et al., 2008). Moreover, this type of extraordinary performance based on intuitive problemsolving is also being demonstrated in rather complex knowledge construction activities (Harteis et al., 2008; Harteis and Billett, 2013).

Recently, Harteis and Billett (2013) argued that although intuitive problem-solving in technology-rich environments (TREs) is not recognised in the same way as it is in different professions, it is an important ability being utilised across all forms of work requiring instantaneous decision making (see also Harteis and Gruber, 2008). Despite the rapid proliferation of technologies in the workplace, research into the professional development and adults' skills for solving problems in TREs is still in its infancy. Therefore, it is not yet clear what kinds of factors influence and are associated with VET adults' strong problem-solving skills in TREs. To guide future workplace learning, we need a better understanding of what kinds of 
skills adults currently have and what kinds of factors are associated with strong performance in TRE problem-solving to develop professional expertise for VET adults that will be needed in their future working lives.

Previously, the problem has been that no accurate international large-scale data have been available with respect to adults' key information-processing skills. The data from the Programme for the International Assessment of Adult Competencies (PIAAC) from the Organisation for Economic Co-operation and Development (OECD) comprise the most comprehensive source of information of adult skills ever undertaken. As a result, the PIAAC information is an extension of prior information sources on adults' skills and competences and makes it possible to identify gaps throughout adults' working careers by predicting current and emerging needs in relation to adults' problem-solving skills in TREs.

\begin{abstract}
Aims
Our previous analysis of the PIAAC data has indicated that despite different educational approaches (school- versus work-based) to VET, the majority of adults with VET in Europe have weak skills or lack skills to solve problems in TREs (Hämäläinen et al., 2014). As a direct result of that, European countries are challenged to find new ways to enhance the quality of VET adults' problemsolving skills in TREs to respond to the requirements of working life. However, in addition to low-performing adults, there are well-performing VET adults when it comes to problem-solving skills in TREs. The starting point for the present study is to explore what distinguishes these good problem-solvers in TRE. This study uses the PIACC data and seeks to understand which factors are associated with VET adults' strong problem-solving skills and what kinds of associations come into view. More specifically, this article focuses on introducing new knowledge with respect to the socio-demographic, work-related and everyday life background factors that contribute to successful VET adults' problem-solving skills. The specific research questions are as follows:
\end{abstract}

$\mathrm{RQ1}$ : What are typical characteristics of strong problem-solvers?

RQ2: Which socio-demographic factors are associated with VET adults' strong performance in problem-solving in TREs?

RQ3: Which factors related to skills use and learning at work are associated with VET adults' strong performance in problem-solving in TREs?

RQ4: Which factors related to skills use and learning outside of working life are associated with VET adults' strong performance in problem-solving in TREs?

\title{
Data and methods
}


We analyse PIAAC data from 11 countries $^{1}$. This selection of countries is based on an earlier study (Hämäläinen et al., 2014) in which the selection was based on the information available in the Cedefop calculations of Eurostat data (i.e. whether they apply a school- or work-based VET approach) and the information in the PIAAC data (i.e. whether data were available on problem-solving in TREs, as not all countries took part in the problem-solving tests; for a detailed description, see Hämäläinen et al., 2014). Our analysis focuses on VET adults who are employed. The number of observations in the resulting dataset was 12,929 .

In the PIAAC data, the problem-solving skills of an individual are measured by 10 plausible values (PVs). These can be seen as alternative (though highly intercorrelated) 'test scores', each estimating the individual's latent proficiency. Together they describe the 'range' where the individual's 'true' proficiency is likely to be located. The canonical approach, following the methodological principles adopted in PIAAC and other international large-scale assessments (see OECD, 2013), is to use all of them in the statistical analyses, to avoid underestimation of population variance and correctly account for the uncertainty in estimating a latent quantity. However, approximate results of adequate precision can be obtained using a single PV. On the one hand, this simplifies the required computations; on the other hand, this enables more versatile data analyses. In what follows, we have based our analyses on the tenth problemsolving PV (PV10). The reason for selecting this specific PV was that in the descriptive statistical analyses, it produced results that were very close to those obtained using all $10 \mathrm{PVs}$. We also made some comparisons between the logistic regression results obtained using all $10 \mathrm{PVs}$ and, alternatively, with PV10 only. The numerical differences were minor and did not lead to dissimilar conclusions.

Our aim is to explore the background variables associated with strong problemsolving skills in TREs as measured in the PIAAC tests. Using the PV10, we divided the VET adults into two groups: strong performers (skill level 3, which is the highest level possible, so individuals with a test score between 341 and 500 points) and the others (skill level 2 or lower, individuals with a test score between 0 and 340 points, and those who could not take the PIAAC test with computer were included also ${ }^{2}$ ). In PIAAC the proficiency levels of problem solving in TREs are defined on the grounds of the complexity of cognitive strategies and

\footnotetext{
${ }^{1}$ More precisely, 5 countries with work-based VET approaches (Austria, Slovak Republic, Czech Republic, Denmark and Germany) and 6 countries with school-based VET approaches (Belgium, Finland, Ireland, the Netherlands, Norway and Poland).

${ }^{2}$ The individuals who could not complete the test were included in the group of 'other' performers because they either indicated a lack of skills to work with computers or failed a basic computer test (e.g. scrolling, dragging), excluding them from the problem-solving in TREs test. In other words, these individuals can reasonably be considered as not being strong performers in problem-solving in TREs.
} 
processes needed in completing the tasks as well as the command of multiple technology environments. At level 3 an individual typically shows command of specific technology applications, ability to navigate across pages and use tools. In addition, adult shows capability to handle tasks involving multiple steps and operators, goals not given beforehand and unexpected outcomes. Finally, at level 3 the respondent is capable of evaluating the relevance of information as well as high inferential integration (see, OECD 2013).

We have considered a number of explanatory background factors, which were categorized into three clusters - see Table A1, appendix. First, a sociodemographic cluster comprising: (1) age, measured continuously but categorized in 10-year-spans; (2) occupational status, differentiating between elementary, semi-skilled blue-collar, semi-skilled white collar and skilled occupations; (3) gender; (4) cultural capital as measured by the number of owned books, namely more or less than 100 books; (5) cultural capital as measured by parents' educational level, differentiating between less than upper secondary education, upper secondary education and higher education; (6) cultural background as measured by language spoken at home, differentiating between native and nonnative speakers; and finally (7) subjective health. A second cluster consists of variables related to workplace skills use and learning, more precisely: (1) numeracy skill-use, (2) ICT skill-use, (3) reading skill-use, (4) writing skill-use, (5) informal learning opportunities, (6) (non-)formal learning opportunities as measured by participation in adult education and training (AET) for job-related reasons, (7) employment type, differentiating between the self-employed and employees; and (8) job position, differentiating between supervisors and others. Finally, a third cluster consists of variables related to everyday life skill use and learning comprising: (1) numeracy skill-use, (2) ICT skill-use, (3) reading skilluse, (4) writing skill-use and (5) (non-)formal learning opportunities as measured by participation in AET for non-job-related reasons. Binary logistic regression models were fitted to the data to examine which factors predict strong problemsolving performance ('other' performers being the reference category).

All data analyses were carried out with the SAS software. Basic descriptive statistics and their standard errors were computed by specific SAS macros provided by the PIAAC Consortium and tailored to follow the methodological principles of the PIAAC study (see OECD, 2013). The logistic regression analyses were performed using the SURVEYLOGISTIC procedure of the SAS software. The regression coefficients were estimated by maximum likelihood, and the variances were estimated under the model-based approach, making use of 
the Taylor series linearization method ${ }^{3}$. All analyses were survey weighted to account for the PIAAC sampling design and possible biases caused by nonresponse.

First, we estimated a multiple logistic regression model for each of the three background factor clusters separately to assess the relative importance of sociodemographic, work-related and everyday skill use and learning factors. Second, we fitted a 'final' logistic model consisting of statistically significant $(p<.05)$ predictors only. The candidate predictors for this final model were selected on the basis of the results from the logistic models of the three factor clusters. Only those factors which showed $p<.10$ in the cluster-wise analyses were selected. From these factors, the final collection of statistically significant predictors was selected by the backward elimination approach, i.e. the non-significant factors were removed one by one from the model with all factors, until only significant factors were left, resulting in a parsimonious model.

\section{Results}

According to the analysis of all $10 \mathrm{PVs}$, only $2.7 \%$ of the employed VET adults in the data showed strong problem-solving skills. Exactly the same proportion was obtained using the PV 10 only. Compared to the 'other' performers, the strong performers were somewhat younger (mean age 34 years versus 42 years), more often male $(65 \%$ vs $56 \%)$ and had more often skilled occupations $(49 \%$ vs $23 \%)$ - see appendix, Table A1. In addition, they tended to have more cultural capital, as measured with parents' education (36\% with at least one parent having a higher education degree, versus $16 \%$ ) and number of books at home (56\% with at least 100 books at home, versus $31 \%$ ). When it comes to skill use at work, active use was more common among the strong performers than among the others, whether the question is about numeracy ( $56 \%$ vs $27 \%$ ), ICT skills ( $41 \%$ vs $17 \%$ ), reading ( $54 \%$ vs $30 \%$ ) or writing ( $43 \%$ vs $28 \%$ ). The results on skill use at home were similar (Table A1). Finally, the strong performers seemed to have participated in adult education and training, both job-related $(68 \%$ vs $46 \%$ ) and non-job-related ( $14 \%$ vs $6 \%$ ), more actively than the others.

In Table 1, we present the results of the binary logistic regressions for each cluster of factors. These results represent the likelihood of attaining a strong performance in TREs. From these figures, we can first observe that the three clusters of explanatory factors are almost equally important in predicting a strong

\footnotetext{
${ }^{3}$ The frequently adopted approach for variance estimation in large-scale assessments is the Jackknife Repeated Replication (JRR) method. This approach is, in general, slightly more robust than the approach adopted here, with respect to possible model misspecifications, but otherwise there is no systematic evidence favouring one approach over the other.
} 
problem-solving performance. As measured with the Nagelkerke R-square, socio-demographic factors explained $13 \%$ of the variation. Workplace skill use and learning explained $10 \%$, and everyday skill use and learning $12 \%$.

\section{Insert Table 1}

Of the socio-demographic factors, age group showed the strongest effect on the likelihood of strong problem-solving skills in TREs, in terms of odds ratios. The older the respondent becomes, the less likely s/he is to attain strong skills in problem-solving. Compared to the 16- to-24 year olds, the odds of 35- to 44 year olds being a less-than-strong problem-solving performers was two (2.16) times larger. For the 45 - to 54 year olds, the odds were more than three (3.30) times larger, and for the 55- to 65 year olds almost seven (6.67) times larger. The difference between the 16- to 24 year olds and 25- to 34 year olds was not statistically significant, however. Having a skilled occupation played a highly significant role as well: those in skilled jobs were far more often strong performers than the others (odds ratios ranged from 2.13 to 4.35 ). Cultural capital, as measured by the number of books at home, also increased the likelihood of strong performance. The odds of being a strong performer was 1.34 times larger among individuals who own more than 100 books compared to individuals who own less than 100 books. Gender also had a significant effect, with men having 1.71 times larger odds than women for being a strong performer. Cultural background, as measured by language spoken at home, had no significant effect, nor did the self-assessed health.

The results of the workplace skill use and learning cluster suggest that only practicing numeracy at work and participation in job-related AET have significant positive effects on the likelihood of strong problem-solving performance at the conventional $5 \%$ level. However, the effects of ICT use at work and writing at work were very close $(p=.055$ and $p=.078$, respectively). Those who had participated in job-related AET were 1.61 times more likely to be strong problemsolving performers. As for the use of numeracy skills, the most active group showed strong performance more often than the other groups ${ }^{4}$.

The picture for the third cluster of variables, everyday skill use and learning, is quite similar to the second cluster. Practising numeracy skills at home and participating in non-job-related AET had positive effects on problem-solving skills. Those who averagely or actively use numeracy skills at home had approximately

\footnotetext{
${ }^{4}$ We changed the reference category of the numeracy at work from 'Passive' to 'Active' to make the group differences more observable.
} 
2.5 times larger odds of being strong problem-solving performers than the 'passive' group. The odds of those who had participated in non-job-related AET was 2.27 times larger than the odds of those who had not. In addition, practising ICT skills at home had an extremely strong influence on strong problem-solving performance; in effect, average and active ICT practitioners had, respectively, odds that were no less than 5.10 and 10.44 times larger than that of the most passive group. It is also worth mentioning that the effect of writing at work was not far from being statistically significant. Instead, the use of reading skills (either at home or at work) did not play a significant role at all after the other skill uses were controlled for.

Table 2 presents the results of the 'final' model, i.e. the logistic model containing those factors (preselected on the basis of the previous cluster-wise analyses), which were found to be significant $(p<.05)$ when considered together. Comparable to the results of the socio-demographic cluster only (see Table 1), age still has a strong impact on the likelihood of strong performance in problemsolving in TREs. In particular, older adults are less likely to be strong problemsolving performers: the odds of 55- to 65 year olds was 5.40 times larger than that of 16- to 24 year olds. Additionally, occupational status and cultural capital (measured as owned books) influence the likelihood of strong performance as well.

Insert Table 2

The results for the cluster on workplace skills and learning indicate that participating in work-related AET increased the odds of being a strong performer by 1.85 . The effect of using numeracy skills was highly significant. The most active practitioners obtained the best results but, surprisingly, the difference from the most passive ones was small. Instead, the average group showed clearly the worst performance. As for writing skills, both average and active practitioners distinguished themselves positively from the passive ones. Overall, the most active practitioners of both numeracy and writing obtained the best problemsolving results.

Finally, the variables in the everyday life cluster had considerable influences as well. More specifically, we observed that the use of ICT skills is positively associated with the likelihood of strong problem-solving performance, with average and active practitioners having, respectively, 2.37 and 3.35 times larger odds of being strong performers than the most passive ones. The influence of using numeracy skills was similar; here the odds ratios for average and active practitioners were 2.56 and 2.71, respectively. Participation in AET during free time (i.e. for non-job-related reasons) also increased the likelihood of strong 
problem-solving performance; the odds of strong performance was 3.24 times higher among those who had participated.

\section{Discussion}

In light of the PIAAC data, our previous studies (Hämäläinen et al., 2014; 2015) showed the critical issue that adults with VET have lower problem-solving performance on average than adults with other educational backgrounds. As problem-solving in TREs is increasingly important in the labour market, there seems to be a gap emerging between what kinds of skills VET adults currently have and what is beneficial in future workplaces. The aim of the present study was to generate a better understanding of the background factors that are associated with VET adults' strong problem-solving performance. As the results pointed out, the socio-demographic factors of age, occupation, and books at home are essential factors. The age factor is known to be related to problemsolving skills in TREs (Hämäläinen et al., 2015). Naturally, the generational differences are intertwined with age, i.e. older adults had a different VET back in their schooling, and they have had different pathways on working life (also see the discussion on the changing workplace in the introduction of this article). Given that one of the places where adults learn, or at least use and maintain their skills, is the workplace (Billett, 2006; Bound and Lin, 2013), it is not surprising that occupational status is highly related to problem-solving skills. In addition to work-related learning, our results also show novel information indicating that cultural capital, the number of books at home, a factor that is actually more related to an adults' everyday life than with his/her occupation, is an important predictor of strong problem-solving skills.

\section{Future directions}

Based on our findings and other related research, we propose three recommendations for enhancing VET adults' continuing professional development and work conditions. First, the challenge is that in workplaces, simple routine tasks are more and more often performed automatically by computer-controlled machines, while modern workers often need to collaborate in teams and are employed to tackle exactly those problems that cannot be tackled automatically by computers or robotics. As a direct result of that, workers with a VET background face concrete problem-solving situations in which knowledge is somehow implicit and directly integrated into practice. Furthermore, most decisions in current workplaces have to be made under time constraints or with restricted or incomplete information, requiring creative problem-solving under those conditions (Harteis and Billett, 2013). However, people with little prior experience regarding successful problem-solving experiences in TRE settings may not have developed adequate knowledge that guides them in 
problem-solving situations (Fischer et al., 2013). We emphasise the importance of group-based working and learning approaches in supporting VET adults' problem-solving in TREs. One solution may be to pay more attention to collaboration between groups of adult workers. For example, communities of practices (Wenger, 1998) may help VET adults to engage in the processes of collective learning in a shared domain in the workplace.

Second, VET adults may not be ready to quickly take over new technologies and to solve problems in changing technological environments. Our results hint that this may be related to the notion that VET adults may not spontaneously engage enough in everyday life learning and in using TRE problem-solving skills outside the workplace. In particular, our findings indicated that participating in job-related and non-job-related AET is favourable for problem-solving skills; however, the effect seems stronger for non-job-related AET. The same is true for ICT skills; while ICT skills at home are of significant importance, ICT skills at work were not significant. Regarding Eraut (2004 a,b), everyday life and informal learning encounters are essential for experiencing, developing, refining, and sharpening what has been learnt previously and generating tacit knowledge and routines that are shaping professional development in workplace settings. In line with this, in addition to novel technology-enhanced workplace learning approaches (e.g. Tynjälä, Häkkinen, \& Hämäläinen, 2014), VET adults' professional development calls for novel ways to support non-formal and informal learning. While these professional development activities can be organised for adults already in the workforce, it may be important to stimulate a lifelong learning attitude throughout the initial vocational education and training.

Third, it seems that VET adults need support for developing their professional competencies, knowledge and skills to better match future workplace needs, since only $2.7 \%$ of the employed VET adults in the data showed strong problemsolving skills. On the one hand, new technological solutions can provide encouragement for solving problems in workplace contexts. On the other hand, the usage of technological tools in itself does not guarantee successful problemsolving in TRE settings. Recently, Harteis and Billett (2013) claimed that experts in intuitive problem-solving situations recognise patterns in complex arrangements that enable them to better respond spontaneously in ways that novices would not be able to. The crucial question relates to how VET adults with limited previous experiences and low problem-solving skills in TREs can develop the ability to recognize patterns in complex arrangements that enable them to respond quickly to problem-solving situations in their working lives. It is pivotal to create support for VET adults to respond to future problem-solving challenges. Previous research in educational contexts has focused on individual (Schank and Abelson, 1977) and collaboration (Kobbe et al., 2007; Fischer et. al., 2013) 
scripts as a successful instructional approach to support problem-solving in TREs (for a detailed description of scripts, see a recent review by Fischer et al., 2013; Kollar et al., 2014). In short, scripts refer to culturally shared knowledge about the world that provides information, for example, about conditions and processes of problem-solving situations (Schank and Abelson, 1977) that may enable the development of VET adults' problem-solving experiences, which then lead to enhanced skill development.

While the results of our study are very informative with respect to providing insight into the general backgrounds of adults with strong problem-solving skills, we have to acknowledge that the nature of our study is explorative and that the relationships found are important, but causality is hard to define. Therefore, our findings highlight the need for further studies. For example, one interesting finding in this study was that writing at work was significantly predicting problemsolving skills (especially for average compared to passive adults), while writing at home was not withheld in the model. With respect to this, further studies are needed to illuminate which writing activities are contributing to the development of problem-solving skills. While the PIAAC data are not fine-tuned enough to investigate this in detail, there is related qualitative research on reflective writing and vocational learning (Boldrini and Cattaneo, 2014).

In sum, VET adults are a heterogeneous group and their needs can vary among professionals. We need several research-based ways to support VET adults' professional and competence development at the individual and collective levels (Bound and Lin, 2013). We have workers who will change occupations and complete different training programmes for different professions (Bresnahan et al., 2002; Crafts, 2004). Thus, development of continuing education is needed. In addition, we will have to develop new workplace learning approaches for workers who will stay at the same workplace, but have changing job descriptions (Maclean and Wilson, 2009; Tuomi-Gröhn and Engeström, 2003). And finally, VET adults who can be identified as 'at-risk' or 'weak' performers may be in danger of exclusion from the labour market due to their insufficient skills and abilities. As previous studies have indicated that low levels of education and limited working history are associated with an increased risk of labour market exclusion (Rosholm, 2001), special attention needs to be paid for developing new prospects for VET adults' lifelong, life wide and workplace learning. An important implication of this study is that this article explored new knowledge about good problem-solvers in TREs with a VET background. This knowledge can serve as a starting point for developing the abovementioned learning approaches. 


\section{Acknowledgements}

This work was supported by the Academy of Finland under Grant number 292466 [the Multidisciplinary Research on Learning and Teaching profile of JYU].

\section{References}

Billett, S. (2006), Work. Change and Workers, Dordrecht, Springer.

Boldrini, E. and Cattaneo, A. (2014), "Scaffolding collaborative reflective writing in a VET curriculum", Vocations and Learning, Vol. 7 No. 2, pp. 145-165.

Bound, H. and Lin, M. (2013), "Developing competence at work", Vocations and Learning, Vol. 6 No. 3, pp. 403-420.

Brand-Gruwel, S. and Stadtler, M. (2011), "Solving information-based problems: Evaluating sources and information”, Learning and Instruction, Vol. 21 No. 2, pp. 175-179.

Bresnahan, T., Brynjolfsson, E., and Hitt, L. (2002), "Information technology, workplace, organisation and the demand for skilled labour: A firm level analysis", Quarterlv Journal of Economics, Vol. 111 No. 1, pp. 339-376.

Crafts, N. (2004), "Steam as a general purpose technology: A growth accounting perspective”, Economic Journal, Vol. 114, pp. 338-351.

Eraut, M. (2004a), "Transfer of knowledge between education and workplace settings", in H. Rainbird, A. Fuller, and A. Munro (Eds.), Workplace Learning in Context London, Routledge, pp. 201-221.

Eraut, M. (2004b), "Informal learning in the workplace", Studies in Continuing Education, Vol. 26 No. 2, pp. 173-247.

European Commission (2013), Work-based learning in Europe - Practices and Policy Pointers (http://ec.europa.eu/education/lifelong-learning-policy/doc/workbased-learning-in-europe_en.pdf. accessed: 18.05.2014)

Eurydice Highlights (2012/2013), The structure of the European education systems 2012/13: schematic diagrams:

http://eacea.ec.europa.eu/education/eurydice/index_en.php.

Fischer, F., Kollar, I., Stegmann, K., and Wecker, C. (2013), "Towards a script theory of guidance in computer-supported collaborative learning", Educational Psvchologist, Vol. 48 No.1, pp. 56-66. 
Frey, C. and Osborne, M. (2013), The future of employment: how susceptible are jobs to computerisation? Retrieved January 15, 2014 from

http://www.oxfordmartin.ox.ac.uk/downloads/academic/The_Future_of_Employm ent.pdf

Goos, M. (2013), How the world of work is changing: A review of the evidence.

ILO Research Paper (pp. 1-54), Retrieved October 26, 2015 from

http://www.ilo.org/public/english/dialogue/actemp/downloads/events/2013/symp/h ow worldofwork changing.pdf

Harteis, C. and Billett, S. (2013), "Intuitive expertise: Theories and empirical evidence", Educational Research Review, Vol. 9, pp. 145-157.

Harteis, C. and Gruber, H. (2008), "Intuition and professional competence: Intuitive versus rational forecasting of the stock market", Vocations and Learning, Vol. 1, pp. 71-85.

Harteis, C., Koch, T., and Morgenthaler, B. (2008), "How intuition contributes to high performance: An educational perspective", US-China Education Review, Vol. 5 No. 1, pp. 68-80.

Herder, E., Koesling, A., Olmedilla, D., Hummel, H., Schoonenboom, J., Moghnieh, A., and Vervenne, L. (2006), "European lifelong competence development: Requirements and technologies for its realisation", Paper presented at the International Workshop in Learning Networks for Lifelong Competence Development, March 30-31, 2006, Sofia, Bulgaria. Retrieved January 15, 2014 from

http://dspace.learningnetworks.org/bitstream/1820/767/1/Paper30.pdf

Hämäläinen, R., De Wever, B., Malin, A. and Cincinnato, S. (2015), "Education and working life: VET adults' problem-solving skills in technology-rich environments", Computers \& Education, Vol. 88, pp. 38-47.

Hämäläinen, R., Cincinnato, S., Malin, A. and De Wever, B. (2014), “VET workers' problem-solving skills in technology-rich environments: European approach", International Journal for Research in Vocational Education and Training, Vol. 1 No. 1, pp. 57-80.

Kende, M. (2015), ICTs for Inclusive Growth: E-Entrepreneurship on the Open Internet. In S. Dutta, T., Geiger, and B. Lanvin (Eds.). The Global Information Technology Report 2015, ICTs for Inclusive Growth. http://www3.weforum.org/docs/WEF_Global_IT_Report_2015.pdf 
Kobbe L., Weinberger A., Dillenbourg P., Harrer A., Hämäläinen R., Häkkinen P., et al. (2007), "Specifying computer-supported collaboration scripts", International Journal of Computer-Supported Collaborative Learning, Vol. 2 No. 2/3, pp. 211224.

Kollar, I. Ufer, S. Reichersdorfer, E. Vogel, F. Fischer, F. and Reiss, K. (2014), "Effects of collaboration scripts and heuristic worked examples on the acquisition of mathematical argumentation skills of teacher students with different levels of prior achievement", Learning and Instruction, Vol. 32, pp. 22-36.

Levy, F. (2010), How technology changes demands for human skills. OECD Education Working Papers, No. 45, OECD Publishing.

http://dx.doi.org/10.1787/5kmhds6czqzq-en

Maclean, R. and Wilson, D. (Eds.) (2009), International Handbook of Education for the Chanaing World of Work: Bridaing Academic and Vocational Training, Netherlands, Springer.

OECD (2012a), Better Skills, Better Jobs, Better Lives: A Strategic Approach to Skills Policies, OECD Publishing. Retrieved October 28, 2015 from http: http://dx.doi.org/10.1787/9789264177338-en

OECD (2012b), Literacy, Numeracy and Problem Solving in Technology-Rich Environments: Framework for the OECD Survey of Adult Skills, Paris, OECD Publishing. Retrieved October 28, 2015 from http: doi:10.1787/9789264128859en

OECD. (2013), Technical Report of the Survey of Adult Skills (PIAAC). Retrieved April 11, 2014 from http:

http://www.oecd.org/site/piaac/ Technical\%20Report 170CT13.pdf

Rosholm, M. (2001), "An analysis of the processes of labour market exclusion and (re-)inclusion (July 2001). IZA Discussion Paper No. 332. Available at SSRN: http://ssrn.com/abstract=278518

Schank, R. C. and Abelson, R. P. (1977), Scripts, Plans, Goals and Understanding, Erlbaum, Hillsdale, NJ.

Tuomi-Gröhn, T. and Engeström, Y. (Eds.). (2003), Between School and Work: New Perspectives on Transfer and Boundary-crossing, Amsterdam, Pergamon.

Tynjälä, P. (2013), "Toward a 3-P model of workplace learning: a literature review", Vocations and Learning. Studies in Vocational and Professional Education, Vol. 6 No. 1, pp. 11-36. 
Tynjälä, P., Häkkinen, P. \& Hämäläinen R., (2014). TEL@work - towards integration of theory and practice. British Journal of Educational Technologv. Vol. 45 No. 6 , pp. 990-1000.

Wenger, E. (1998), Communities of Practice: Learning Meaning and /dentity, Cambridge, UK, Cambridge University Press.

\section{Biographies:}

Raija Hämäläinen, $\mathrm{PhD}$, is a full professor of technology-enhanced learning (TEL) at University of Jyväskylä (Faculty of Education). Her research has been based on active international collaboration in theoretical, empirical and design issues of TEL. Her expertise also lies on developing new prospects for supporting adults' professional competences to better meet the current workplace needs.

Bram De Wever, Phd, is associate professor at the Department of Educational Studies at Ghent University, where he teaches courses on adult education, higher education, and powerful learning environments. His research is focusing on technology-enhanced learning and instruction, peer assessment and feedback, computer-supported collaborative learning activities, and inquiry learning in higher education and adult education.

Kari Nissinen, PhD (statistics), is a senior researcher in Finnish Institute for Educational Research, University of Jyväskylä. His main responsibilities are management and statistical analyses of large-scale assessment (PISA, TIMSS, PIRLS, PIAAC) data sets. He has a long experience in statistical data analysis, and his expertise areas are linear and generalized linear models, multilevel and mixed models, multivariate statistics and survey methodology.

Sebastiano Cincinnato is a $\mathrm{PhD}$ researcher at the Teacher Education Department of the Vrije Universiteit Brussel (Brussels, Belgium). His research revolves around study performance in Flemish (Belgium) higher education. More in particular, the research focuses on both individual and programme characteristics contributing to the likelihood of success in higher education, with a special interest for the intersectionality of social inclusion/exclusion indicators. 
Table 1. Likelihood of strong performance in problem-solving in TRE, outcomes from the binary logistic regression, per cluster

$\underline{\text { Odds }}$

$\underline{\text { ratio }}$

$\underline{b} \quad \underline{\mathrm{SE}} \quad \underline{(\mathrm{OR})} \quad \underline{1 / \mathrm{OR}}$

\begin{tabular}{|c|c|c|c|c|}
\hline \multicolumn{5}{|l|}{ Cluster 1: Socio-demographic factors } \\
\hline \multicolumn{5}{|l|}{$R^{2}($ Nagelkerke $)=.128$} \\
\hline \multirow{2}{*}{\multicolumn{5}{|c|}{ 1. Age $\left[\chi^{2}(4)=23.39, p<.001\right]$}} \\
\hline & & & & \\
\hline $25-34$ & -.09 & .27 & .91 & 1.10 \\
\hline $35-44$ & -.77 & .30 & .46 & 2.16 \\
\hline $45-54$ & $-1.19^{* *}$ & .35 & .30 & 3.30 \\
\hline $55-65$ & $-1.90^{* *}$ & .66 & .15 & 6.67 \\
\hline \multicolumn{5}{|l|}{ 2. Occupational status ${ }^{a}\left[\chi^{2}(3)=34.18, p<.001\right]$} \\
\hline Elementary occupations & -1.05 & .64 & .35 & 2.86 \\
\hline Semi-skilled blue-collar occupations & $-1.46^{* * *}$ & .26 & .23 & 4.35 \\
\hline Semi-skilled white-collar occupations & $-.76^{* * *}$ & .23 & .47 & 2.13 \\
\hline \multirow{2}{*}{\multicolumn{5}{|c|}{ Skilled occupations (ref) }} \\
\hline & & & & \\
\hline \multicolumn{4}{|l|}{ Female (ref) } & .58 \\
\hline \multicolumn{5}{|c|}{ 4. Cultural capital: books at home $\left[\chi^{2}(1)=16.93, p<.001\right]$} \\
\hline Min. 100 books at home & $.29^{* * *}$ & .07 & 1.34 & .75 \\
\hline \multicolumn{5}{|c|}{$\begin{array}{l}\text { 5. Cultural capital: parental education }\left[\chi^{2}(2)=6.46, p=.040\right] \\
\text { Min. one parent upper secondary education (ref) }\end{array}$} \\
\hline Both parents less than upper secondary education & -.18 & .32 & .84 & 1.19 \\
\hline Min. one parent higher education & $.50^{*}$ & .21 & 1.65 & .60 \\
\hline \multicolumn{5}{|l|}{ 6. Cultural background $\left[\chi^{2}(1)=1.04, p=.308\right]$} \\
\hline Native speaker (ref) & & & & \\
\hline Non-native speaker & .54 & .53 & 1.72 & .58 \\
\hline \multicolumn{5}{|l|}{ 7. Subjective health $\left[\chi^{2}(1)=0.20, p=.658\right]$} \\
\hline Less than good (ref) & & & & \\
\hline At least good & -.05 & .11 & .95 & 1.05 \\
\hline
\end{tabular}

Cluster 2: Work-related learning factors

$R^{2}($ Nagelkerke $)=.100$

1. Numeracy at work $^{\mathrm{b}}\left[\chi^{2}(2)=13.60, p=.001\right]$

$$
\mathrm{N}=\mathbf{1 1 , 3 1 2}
$$

$\begin{array}{lllll}\text { Passive } & -.54 & .32 & .58 & 1.72\end{array}$

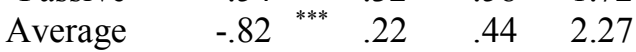

2. ICT at work ${ }^{\mathrm{b}}\left[\chi^{2}(2)=5.79, p=.055\right]$

Active (reference)

Passive (reference)

$\begin{array}{lllll}\text { Average } & .65 & .36 & 1.92 & .52 \\ \text { Active } & 90 & .57 & 2.46 & .41\end{array}$

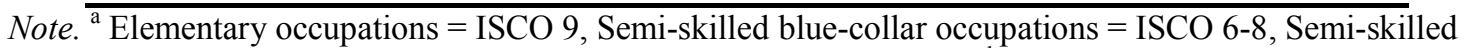
white-collar occupations $=$ ISCO 4-5, Skilled occupations $=$ ISCO 1-3 ${ }^{\mathrm{b}}$ Passive $=$ lowest $20 \%$, Average $=$ $20^{\text {th }}$ to $60^{\text {th }}$ percentile, Active $=$ highest $40 \%{ }^{*} \mathrm{p}<.05,{ }^{* *} \mathrm{p}<.01,{ }^{* * *} \mathrm{p}<.001$. 
Table 1. (Continued)

\section{$\underline{\text { Odds }}$ \\ $\underline{\text { ratio }}$ \\ $\underline{\mathrm{b}} \quad \underline{\mathrm{SE}} \underline{\underline{\mathrm{OR}})} \quad \underline{1 / \mathrm{OR}}$}

3. Reading at work ${ }^{\mathrm{b}}\left[\chi^{2}(2)=.48, p=.812\right]$

Passive (reference)

$\begin{array}{rrrrr}\text { Average } & .16 & .46 & 1.18 & .85 \\ \text { Active } & .28 & .51 & 2.46 & .41\end{array}$

4. Writing at work ${ }^{\mathrm{b}}\left[\chi^{2}(2)=5.10, p=.078\right]$

Active

Passive (reference)

$\begin{array}{rllll}\text { Average } & .87^{*} & .38 & 2.39 & .42 \\ \text { Active } & .71 & .38 & 2.03 & .49\end{array}$

5. (Informal) learning at work ${ }^{\mathrm{b}}\left[\chi^{2}(2)=2.46, p=.292\right]$

Passive (reference)

$\begin{array}{lllll}\text { Average } & .14 & .29 & 1.15 & .87\end{array}$

\begin{tabular}{|c|c|}
\hline Active & -.24 \\
\hline
\end{tabular}

6. Adult Education and Training $\left[\chi^{2}(1)=4.86, p=.027\right]$

Did not participate for job-related reasons (ref)

Participated for job-related reasons

7. Employment type $\left[\chi^{2}(1)=2.09, p=.149\right]$

Employee (ref)

Self-employed

$.47^{*} \quad .22 \quad 1.61$

8. Job position $\left[\chi^{2}(1)=.09, p=.765\right]$

Other (ref)

Supervisor

\section{Supervisor}

$\begin{array}{lll}.06 & .22 & 1.07\end{array}$

.94

Cluster 3: Everyday life learning and other factors

$$
\begin{array}{r}
R^{2}(\text { Nagelkerke) }=.118 \\
N=11,328
\end{array}
$$

1. Numeracy at home ${ }^{\mathrm{b}}\left[\chi^{2}(2)=10.46, p=.005\right]$

Passive (ref)

Average

Active

2. ICT at home ${ }^{\mathrm{b}}\left[\chi^{2}(2)=39.64, p<.001\right]$

$.94^{* *} \quad .31 \quad 2.56$

Passive (ref)

Average

$1.63^{* * *} \quad .40 \quad 5.10 \quad .20$

3. Reading at home ${ }^{\mathrm{b}}\left[\chi^{2}(2)=.19, p=.908\right]$

Active $\quad 2.35^{* * *} \quad .39 \quad 10.44 \quad .10$

Passive (ref)

$\begin{array}{lllll}\text { Average } & -.16 & .38 & .85 & 1.17\end{array}$

$\begin{array}{lllll}\text { Active } & -.17 & .41 & .84 & 1.18\end{array}$

4. Writing at home ${ }^{\mathrm{b}}\left[\chi^{2}(2)=5.43, p=.066\right]$

Passive (ref)
Average
Active

$\begin{array}{llll}.69^{*} & .31 & 1.99 & .50\end{array}$

$\begin{array}{llll}.39 & .36 & 1.48 \quad .68\end{array}$

5. Adult Education and Training $\left[\chi^{2}(1)=7.34, p=.007\right]$

Did not participate for non-job-related reasons (ref)

$\begin{array}{llllll}\text { Participated for non-job-related reasons } & .82^{* *} & .30 & 2.27 & .44\end{array}$

Note. ${ }^{\mathrm{b}}$ Passive $=$ lowest $20 \%$, Average $=20^{\text {th }}$ to $60^{\text {th }}$ percentile, Active $=$ highest $40 \% .{ }^{*} \mathrm{p}<.05,{ }^{* *} \mathrm{p}<.01$, *** $\mathrm{p}<.001$. 
Table 2. Likelihood of strong performance in problem-solving in TRE, outcomes from the binary logistic regression, final model

\begin{tabular}{|c|c|c|c|c|c|}
\hline Cluster 1: Socio-demographic factors & $\underline{b}$ & & $\underline{\mathrm{SE}}$ & $\begin{array}{l}\frac{\text { Odds }}{\text { ratio }} \\
\frac{\text { (OR) }}{\text { (OR }}\end{array}$ & $\underline{1 / \mathrm{OR}}$ \\
\hline \multicolumn{6}{|l|}{ 1. Age $\left[\chi^{2}(4)=24.21, p<.001\right]$} \\
\hline \multicolumn{6}{|l|}{$16-24$ (ref) } \\
\hline $25-34$ & -.19 & & .29 & .82 & 1.21 \\
\hline $35-44$ & -.84 & ** & .30 & .43 & 2.31 \\
\hline $45-54$ & -1.16 & ${ }^{* *}$ & .35 & .31 & 3.19 \\
\hline $55-65$ & -1.69 & & .62 & .19 & 5.40 \\
\hline \multicolumn{6}{|l|}{ 2. Occupational status ${ }^{\mathrm{a}}\left[\chi^{2}(3)=10.78, p=.013\right]$} \\
\hline Elementary occupations & -.11 & & .62 & .89 & 1.12 \\
\hline Semi-skilled blue-collar occupations & -.74 & ** & .28 & .48 & 2.10 \\
\hline Semi-skilled white-collar occupations & -.66 & $* *$ & .24 & .52 & 1.93 \\
\hline \multicolumn{6}{|l|}{ Skilled occupations (ref) } \\
\hline \multirow{2}{*}{\multicolumn{6}{|c|}{$\begin{array}{l}\text { 3. Cultural capital: books at home }\left[\chi^{2}(1)=9.14, p=.002\right] \\
\text { Less than } 100 \text { books at home (ref) }\end{array}$}} \\
\hline & & & & & \\
\hline Min. 100 books & .23 & ** & .07 & 1.25 & .80 \\
\hline \multicolumn{6}{|l|}{ Cluster 2: Work-related learning factors } \\
\hline \multicolumn{6}{|l|}{ 1. Numeracy at work ${ }^{b}\left[\chi^{2}(2)=12.12, p=.002\right]$} \\
\hline Passive & -.34 & & .29 & .71 & 1.41 \\
\hline Average & -.77 & *** & .22 & .46 & 2.16 \\
\hline \multicolumn{6}{|l|}{ Active (ref) } \\
\hline \multicolumn{6}{|l|}{ 2. Writing at work ${ }^{\mathrm{b}}\left[\chi^{2}(2)=8.87, p=.012\right]$} \\
\hline \multicolumn{6}{|l|}{ Passive (ref) } \\
\hline Average & .91 & ** & .31 & 2.48 & .40 \\
\hline Active & .64 & * & .30 & 1.89 & .53 \\
\hline \multirow{2}{*}{\multicolumn{6}{|c|}{$\begin{array}{l}\text { 3. Adult Education and Training }\left[\chi^{2}(1)=7.95, p=.005\right] \\
\text { Did not participate for iob-related reasons (ref) }\end{array}$}} \\
\hline & & & & & \\
\hline Participated for job-related reasons & \multicolumn{5}{|c|}{$\begin{array}{r}\text { Did not participate for job-related reasons (ref) } \\
\text { Participated for job-related reasons }\end{array}$} \\
\hline \multicolumn{6}{|l|}{ Cluster 3: Everyday life learning and other factors } \\
\hline \multicolumn{6}{|l|}{ 1. Numeracy at home ${ }^{\mathrm{b}}\left[\chi^{2}(2)=9.81, p=.007\right]$} \\
\hline Average & .94 & $* *$ & .32 & 2.56 & .39 \\
\hline Active & 1.00 & ** & .34 & 2.71 & .37 \\
\hline \multicolumn{6}{|l|}{ 2. ICT at home ${ }^{\mathrm{b}}\left[\chi^{2}(2)=9.55, p=.008\right]$} \\
\hline \multicolumn{6}{|l|}{ Passive (ref) } \\
\hline Average & .86 & * & .40 & 2.37 & .42 \\
\hline Active & 1.21 & $* *$ & .40 & 3.35 & .30 \\
\hline \multicolumn{6}{|c|}{ 3. Adult Education and Training $\left[\chi^{2}(2)=13.90, p<.001\right]$} \\
\hline Participated for non-job-related reasons & 1.18 & $* * *$ & .32 & 3.24 & .31 \\
\hline$\overline{\mathrm{R}^{2} \text { (Nagelkerke) }}$ & .19 & & & & \\
\hline & 12,578 & & & & \\
\hline
\end{tabular}

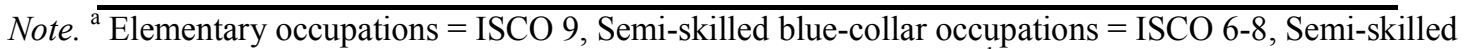
white-collar occupations $=$ ISCO 4-5, Skilled occupations $=$ ISCO 1-3. ${ }^{b}$ Passive $=$ lowest $20 \%$, Average $=$ $20^{\text {th }}$ to $60^{\text {th }}$ percentile, Active $=$ highest $40 \%{ }^{*} \mathrm{p}<.05,{ }^{* *} \mathrm{p}<.01,{ }^{* * *} \mathrm{p}<.001$ 
Table A1. Descriptive sample statistics (weighted)

\begin{tabular}{|c|c|c|c|c|}
\hline & \multicolumn{4}{|c|}{ Problem-solving in TRE } \\
\hline & \multicolumn{2}{|c|}{ Other } & \multicolumn{2}{|c|}{ Strong } \\
\hline & Mean & $\underline{\%}$ & Mean & $\underline{\%}$ \\
\hline \multicolumn{5}{|l|}{ Cluster 1: Socio-demographic factors } \\
\hline 1. Age & 41.5 & & 34.0 & \\
\hline $16-24$ & & 6.5 & & 12.0 \\
\hline $25-34$ & & 20.7 & & 40.7 \\
\hline $35-44$ & & 27.4 & & 26.1 \\
\hline 45-54 & & 29.7 & & 17.1 \\
\hline $55-65$ & & 15.7 & & 4.2 \\
\hline \multicolumn{5}{|l|}{ 2. Occupational status ${ }^{a}$} \\
\hline Elementary occupations & & 6.7 & & 3.4 \\
\hline Semi-skilled blue-collar occupations & & 37.5 & & 18.5 \\
\hline Semi-skilled white-collar occupations & & 33.3 & & 29.5 \\
\hline Skilled occupations & & 22.5 & & 48.6 \\
\hline \multicolumn{5}{|l|}{ 3. Gender } \\
\hline Male & & 56.2 & & 64.9 \\
\hline Female & & 43.8 & & 35.1 \\
\hline \multicolumn{5}{|l|}{ 4. Cultural capital: books at home } \\
\hline Less than 100 books at home & & 68.6 & & 44.5 \\
\hline Min. 100 books at home & & 31.4 & & 55.5 \\
\hline \multicolumn{5}{|l|}{ 5. Cultural capital: parental education } \\
\hline Both parents less than upper secondary education & & 22.1 & & 9.4 \\
\hline Min one parent upper secondary education & & 61.7 & & 54.2 \\
\hline Min. one parent higher education & & 16.3 & & 36.4 \\
\hline \multicolumn{5}{|l|}{ 6. Cultural background } \\
\hline Native speaker & & 92.6 & & 95.9 \\
\hline Non-native speaker & & 7.4 & & 4.1 \\
\hline \multicolumn{5}{|l|}{ 7. Subjective health } \\
\hline Less than good & & 10.4 & & 8.5 \\
\hline At least good & & 89.6 & & 91.5 \\
\hline \multicolumn{5}{|l|}{ Cluster 2: Work-related learning factors } \\
\hline \multicolumn{5}{|l|}{ 1. Numeracy at work ${ }^{b}$} \\
\hline Passive & & 41.4 & & 22.8 \\
\hline Average & & 31.8 & & 20.8 \\
\hline Active & & 26.8 & & 56.4 \\
\hline \multicolumn{5}{|l|}{ 2. ICT at work ${ }^{b}$} \\
\hline Passive & & 60.2 & & 23.6 \\
\hline Average & & 23.3 & & 35.4 \\
\hline Active & & 16.5 & & 40.9 \\
\hline
\end{tabular}

Note ${ }^{\text {a }}$ Elementary occupations $=$ ISCO 9, Semi-skilled blue-collar occupations = ISCO 6-8, Semi-skilled white-collar occupations $=$ ISCO 4-5, Skilled occupations $=$ ISCO 1-3. ${ }^{\mathrm{b}}$ Passive $=$ lowest $20 \%$, Average $=$ $20^{\text {th }}$ to $60^{\text {th }}$ percentile, Active $=$ highest $40 \%$. 
Table A1. (Continued)

\begin{tabular}{|c|c|c|}
\hline \multicolumn{3}{|c|}{ Problem-solving in TRE } \\
\hline & & Othe \\
\hline Mean & $\%$ & Mean \\
\hline
\end{tabular}

3. Reading at work ${ }^{\mathrm{b}}$

$\begin{array}{rrr}\text { Passive } & 29.3 & 8.7 \\ \text { Average } & 40.6 & 36.9 \\ \text { Active } & 30.1 & 54.4 \\ & & \\ \text { Passive } & 37.7 & 8.9 \\ \text { Average } & 34.4 & 48.6 \\ \text { Active } & 27.9 & 42.5 \\ & & \\ \text { Passive } & 28.6 & 19 \\ \text { Average } & 43.1 & 53 \\ \text { Active } & 28.3 & 28\end{array}$

6. Adult Education and Training (AET)

Did not participate for job-related reasons

54.4

31.8

Participated for job-related reasons

45.6

68.2

7. Contract type

Employee

87.9

88.9

Self-employed

12.1

11.1

8. Job position

Supervisor

26.2

34.8

Other

73.8

65.2

Cluster 3: Everyday life learning and other factors

1. Numeracy at home ${ }^{b}$

$\begin{array}{rrr}\text { Passive } & 28.6 & 7.8 \\ \text { Average } & 40.7 & 41 \\ \text { Active } & 30.7 & 51.2\end{array}$

2. ICT at home ${ }^{\text {b }}$

$\begin{array}{rrr}\text { Passive } & 41.3 & 7.8 \\ \text { Average } & 34.7 & 36.5 \\ \text { Active } & 24 & 55.6\end{array}$

3. Reading at home ${ }^{\mathrm{b}}$

$\begin{array}{rrr}\text { Passive } & 20.9 & 6.4 \\ \text { Average } & 43.7 & 35.3 \\ \text { Active } & 35.4 & 58.3\end{array}$

4. Writing at home ${ }^{\mathrm{b}}$

$\begin{array}{rrr}\text { Passive } & 36.4 & 9.9 \\ \text { Average } & 36.3 & 49.8 \\ \text { Active } & 27.3 & 40.4\end{array}$

5. Adult Education and Training

$94.5 \quad 85.9$

$\begin{array}{lrl}\text { Participated for non-job-related reasons } & 5.5 & 14.1\end{array}$

Note ${ }^{\text {a }}$ Elementary occupations $=$ ISCO 9, Semi-skilled blue-collar occupations $=$ ISCO 6-8, Semi-skilled white-collar occupations $=$ ISCO 4-5, Skilled occupations $=$ ISCO 1-3. ${ }^{\mathrm{b}}$ Passive $=$ lowest $20 \%$, Average $=$ $20^{\text {th }}$ to $60^{\text {th }}$ percentile, Active $=$ highest $40 \%$. 